\title{
Rheological Behavior of Carbon Nanotubes as an Additive on Lithium Grease
}

\author{
Alaa Mohamed, ${ }^{1,2}$ Aly Ahmed Khattab, ${ }^{2}$ Tarek Abdel Sadek Osman, ${ }^{2}$ and Mostafa Zaki ${ }^{1}$ \\ ${ }^{1}$ Production Engineering and Printing Technology Department, Akhbar El Yom Academy, Giza 12211, Egypt \\ ${ }^{2}$ Mechanical Design and Production Engineering Department, Faculty of Engineering, Cairo University, Giza 12211, Egypt
}

Correspondence should be addressed to Alaa Mohamed; alaa_elking@hotmail.com

Received 14 July 2013; Revised 28 July 2013; Accepted 4 August 2013

Academic Editor: Hongmei Luo

Copyright (C) 2013 Alaa Mohamed et al. This is an open access article distributed under the Creative Commons Attribution License, which permits unrestricted use, distribution, and reproduction in any medium, provided the original work is properly cited.

The rheological behaviors of carbon nanotubes (CNTs) as an additive on lithium grease at different concentrations were examined under various settings of shear rate, shear stress, and apparent viscosity. The results indicated that the optimum content of the CNTs was $2 \%$. These experimental investigations were evaluated with a Brookfield Programmable Rheometer DV-III ULTRA. The results indicated that the shear, stress and apparent viscosity increase with the increase of CNTs concentration. The microstructure of CNTs and lithium grease was examined by high resolution transmission electron microscope (HRTEM) and scanning electron microscope (SEM). The results indicated that the microscopic structure of the lithium grease presents a more regular and homogeneous network structure, with long fibers, which confirms the rheological stability.

\section{Introduction}

Grease is a solid or semifluid which would normally have been employed together with a thickener, additive, and antioxidant agent. The fluid lubricant that performs the actual lubrication can be petroleum (mineral oil), synthetic oil, or vegetable oil. The thickener gives grease its characteristic consistency and is sometimes believed as a "sponge" that holds the oil in place [1]. The majority of greases on the market are composed of mineral oil blended with a soap thickener. Additives enhance the performance and protect the grease and lubricate surfaces. The influence of the rheological properties of CNTs additives is very important for all the grease lubricating bearings. To characterize a lubricant comprehensively, the rheological properties at all working conditions, pressures, and temperatures have to be known [2]. Grease is widely used as a lubricant in the wheel assembly, journal bearings, and rolling element bearings. Grease is also used in other areas that need occasional service like the brake or stopper assembly to help keep these fittings rust-free and make removal of dirt and grime easier. Grease is applied to machines that can be lubricated infrequently and where lubricating oil would not stay in position. It also acts as a barrier to prevent entering of water and the incompressible materials. CNTs used as a performance enhancing additive in gear lubricants for extended lifetimes, lower operating costs, and improved power efficiency. Numerous laboratory investigations and industrial experience indicate that using of CNTs has significant advantages compared to conventional solid lubricants in both mild and extreme pressure conditions.

Lubricating grease consistency has been evaluated for years with cone penetration test ASTM-D217. The test measures the distance in tenths of a millimeter to which a standard metal cone will penetrate into the grease surface under standard conditions. This single numerical value has been proven to be inadequate to estimate the real consistency of lubricating grease under dynamic conditions. It ignores the non-Newtonian flow behavior characteristic to grease. In the past few years, rheology has been introduced as a new method to better understand and evaluate the real behavior of lubricating grease. Rheology takes into account the influence of shear rate, shear stress, temperature, and time. By measuring the viscosity with both rotational and capillary rheometer, it is possible to see the effect of shear rate on grease consistency which strongly influences the lubricating capability of greases under load [3].

The aim of this work is to evaluate the rheological behaviors of carbon nanotubes (CNTs) as an additive on lithium 
TABLE 1: Composition of the tested grease.

\begin{tabular}{lc}
\hline Base oil & Mineral oil \\
Soap thickener & Lithium \\
Penetration $\left(1 / 10 \mathrm{~mm}\right.$ at $\left.25^{\circ} \mathrm{C}\right)$ & 280 \\
Dropping point & $180^{\circ} \mathrm{C}$ \\
Viscosity of base oil at $40^{\circ} \mathrm{C}$ & $150 \mathrm{cSt}$ \\
\hline
\end{tabular}

grease at different concentrations and study the microstructure of lithium grease.

\section{Experimental Methodology}

2.1. Syntheses of Carbon Nanotubes and Lithium Grease. CNTs were synthesized by the electric arc discharge. The arc is generated between two electrodes (size $\varphi 6 \times 100 \mathrm{~mm}$ ) using distilled water. The cathode and the anode are from graphite (99.9\% pure) and was performed under AC current, $75 \mathrm{~A}$ and $238 \mathrm{~V}$.

Grease that was used in this work was commercially available; the main physical-chemical properties of the grease are presented in Table 1. The grease is lithium based and has good heat resistance, water resistance, and mechanical stability. In order to study the rheological behavior of carbon nanotubes as an additives on lithium grease, carbon nanotubes were added into lithium grease at different concentrations $(0.5,1$, 2 , and $3 \mathrm{wt} . \%)$. The carbon nanotube particles were dispersed well in the grease in an ultrasonic bath.

2.2. Structural Characterization. The size and morphology of carbon nanotube were characterized with high resolution transmission electron microscopy (HRTEM) (JEOL JEM 2100 ) with an accelerating voltage of $200 \mathrm{kV}$.

The grease structure was investigated by a (JEOL JSM$5600 \mathrm{LV}$ ) scanning electron microscope (SEM) with an accelerating voltage of $30 \mathrm{kV}$, resolution of $3.5 \mathrm{~nm}$, probe current of $\left(10^{-12}\right.$ to $\left.10^{-6}\right) \mathrm{A}$.

2.3. Viscometer (Brookfield Programmable Rheometer DV-III Ultra). Rheological measurements were performed on a Brookfield Programmable Rheometer DV-III ultra used in conjunction with Brookfield software, RHEOCALC V.2. Through RHEOCALC, all rheometer functions (rotational speed, instrument $\%$ torque scale, time interval, and set temperature) are controlled by a computer. The corresponding shear stress, shear rate, dynamic viscosity, mathematical model, confidence of fit, and the consistency index were also recorded through the software. The temperature was controlled by connection with bath controller HT-107 and measured by the attached temperature probe.

The Brookfield DV-III Ultra Programmable Rheometer measures fluids and semifluid parameters of shear stress and apparent viscosity at given shear rates. The principle of operating the DV-III Ultra is to drive a spindle (which is immersed into the test fluid) through a calibrated spring. The viscous drag of the fluid against the spindle is measured by the spring deflection. Spring deflection is measured with

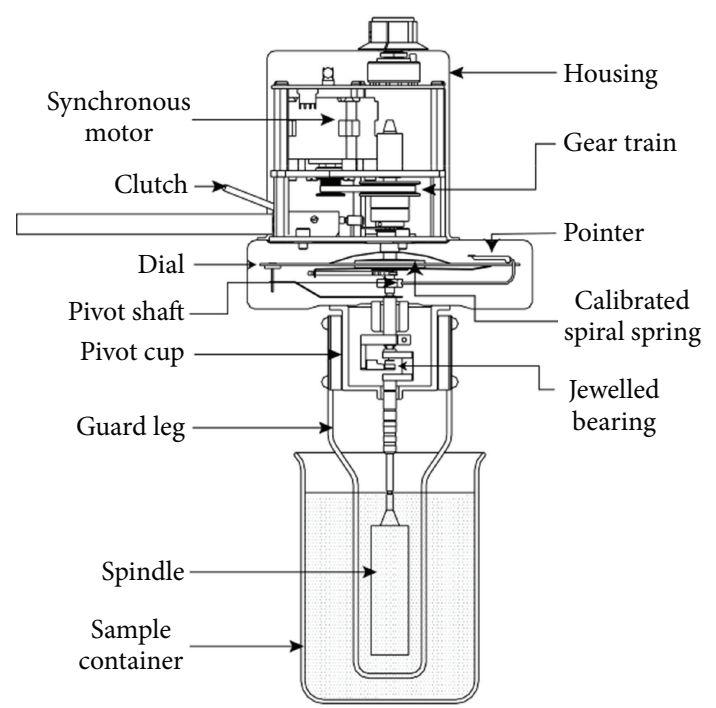

FIGURE 1: The principle of Brookfield DV-III ultra.

a rotary transducer. The viscosity measurement range of the DV-III Ultra (in centipoises or CP) is determined by the rotational speed of the spindle, the size and shape of the spindle, the container in which the spindle is rotated, and the full scale torque of the calibrated spring. The schematic of the instrument is illustrated in Figure 1.

Before carrying out measurements, rheometer DV-III Ultra is turned on, leveled, and autozeroed. The level is adjusted using the three feet on the bottom of the base and confirmed by the bubble on the top of the head. The feet are adjusted until the bubble is inside the center target and sets the level prior to autozero. All measurements have been carried out with cone radius $24 \mathrm{~mm}$ and with $0.8^{\circ}$ cone angle; this gives the gap height of $0.1 \mathrm{~mm}$ at the circumference of the cone.

\section{Results and Discussion}

3.1. Structural Characterization of Carbon Nanotubes. High resolution transmission electron microscope (HRTEM) image of CNTs shown in Figure 2 shows the presence of different structures in the sample and that the average size of the nanoparticles is about $10 \mathrm{~nm}$ in diameter and $1-25 \mu \mathrm{m}$ in length.

Figure 3 shows the SEM image of CNTs dispersed in lithium hydroxystearate (soap) fiber. It can be seen that there is no apparent aggregation of CNTs, indicating that the CNTs could be well dispersed in lithium grease, and it can be observed that the microscopic structure of lithium grease presents a more regular and homogeneous network structure, with long fibers, which confirm the rheological stability.

3.2. Rheological Behavior of Carbon Nanotubes as an Additives on Lithium Grease. Many models are available to describe rheological properties of lithium grease such as Bingham model, Herschel-Bulkley model, Casson model, Bauer model, 


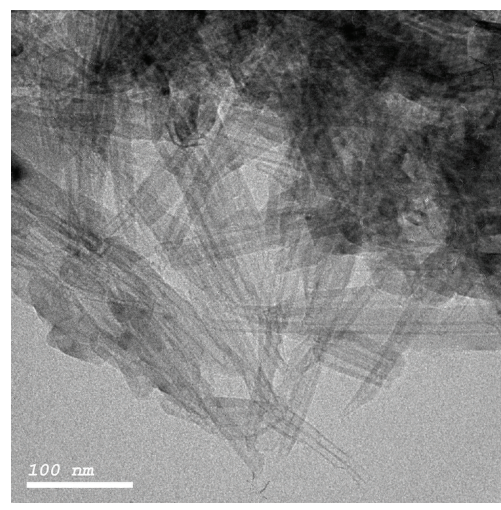

(a)

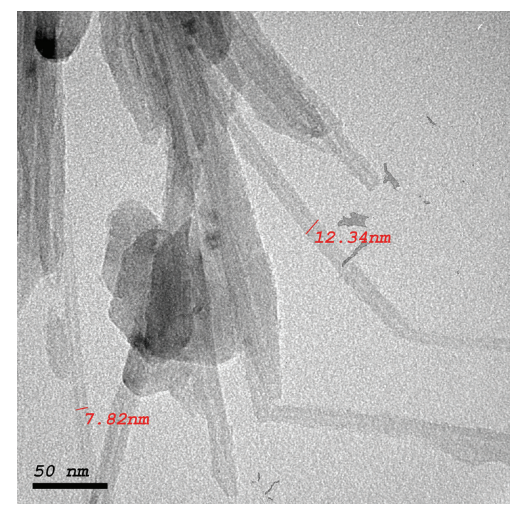

(b)

FIgURE 2: HRTEM images of CNTs.

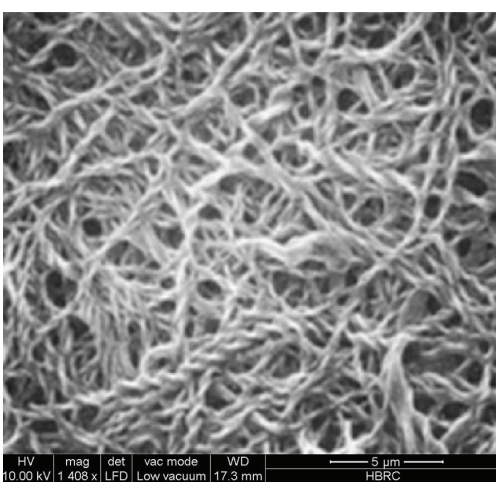

(a)

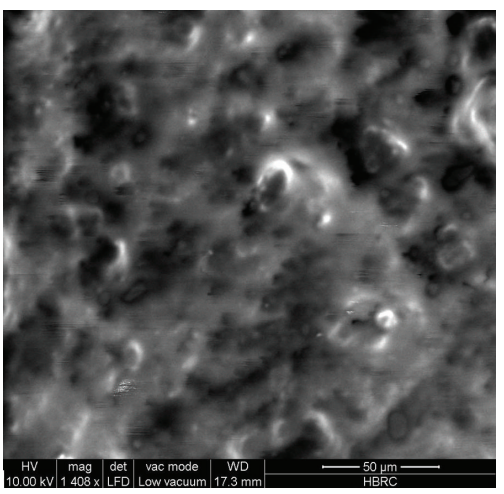

(c)

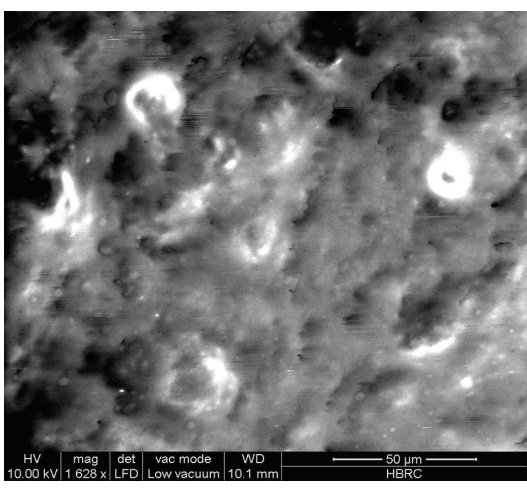

(b)

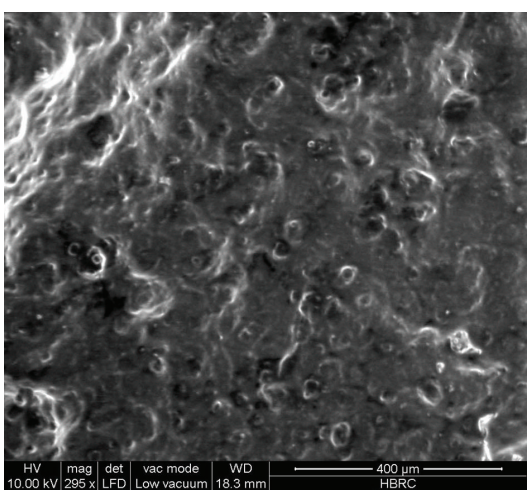

(d)

Figure 3: SEM image of grease with (a) base grease, (b) $0.5 \%$ CNTs, (c) $1 \%$ CNTs, and (d) $2 \%$ CNTs.

Balan model, Papanastasiou model, and Dorier and Tichy model.

The rheological results from the measurements with the cone and plate rheometer, that are shown in Figures 4 and 5 represent the effect of carbon nanotube additives on lithium grease with shear stress and viscosity.

Figures 4 and 5 give the shear stress and apparent viscosity as a function of shear rate for lithium grease alone and that containing different concentrations $(0.5,1,2$, and $3 \mathrm{wt} . \%)$ of CNTs. It can be seen that the shear stress and apparent viscosity of the lithium grease containing $2 \mathrm{wt} . \%$ CNTs are much higher and more stable than that of pure lithium grease at all shear rates. At this point, the shear stress and apparent viscosity could be increased by $67.3 \%$ and $81.8 \%$, respectively. The shear stress of base grease and the grease containing CNTs becomes larger with the increase of shear rate and with the increase of the percentage of carbon nanotube additives on lithium grease.

The apparent viscosity of base grease and the grease containing CNTs becomes larger with the decrease of shear rate 


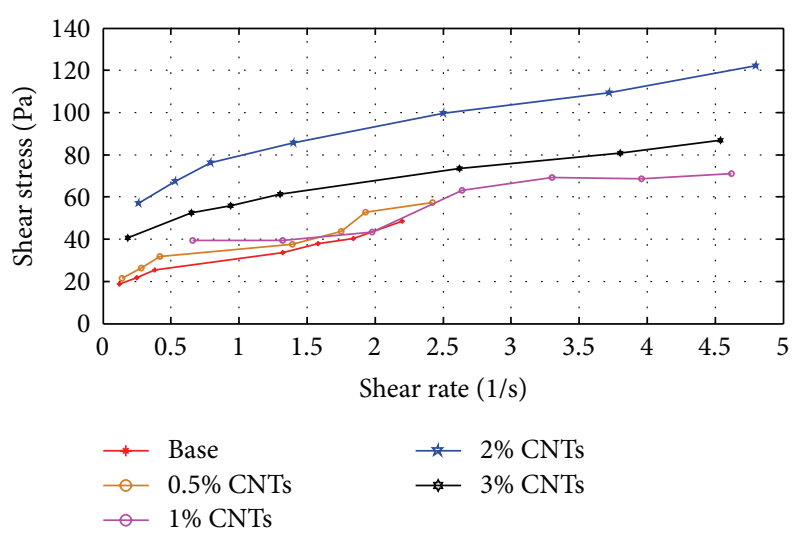

Figure 4: Shear stress of the grease samples.

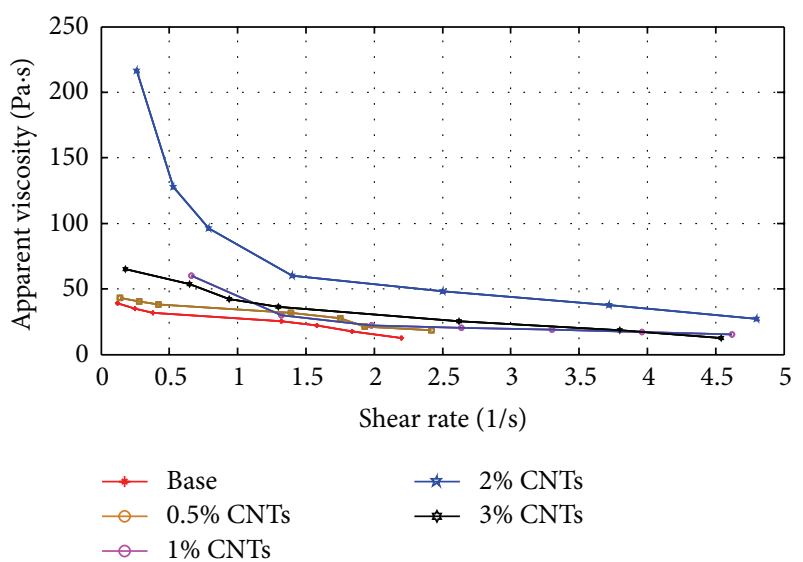

FIGURE 5: Apparent viscosity of the grease samples.

and increases with increasing the percentage of carbon nanotube additives on lithium grease. These experiments were carried out under stationary conditions, to avoid thixotropic behavior. Therefore, the result indicates that all the samples show a large shear thinning behaviour. At low strain rates, the values of apparent viscosity follow quite well the classification found for the yield stress.

\section{Conclusions}

According to the above results and discussion, the conclusions can be summarized as follows.

(1) CNTs were successfully synthesized by electric arc discharge method. The synthesized CNTs have an average diameter of $10 \mathrm{~nm}$ and could be well dispersed in lithium grease.

(2) A rheological characterization, including apparent viscosity, shear stress, and shear rate, was carried out at different concentrations of CNTs. The grease response was studied at constant temperature and time, which led to a real mechanical spectroscopic investigation.
(3) The microstructure of lithium grease at different concentrations was confirmed by scanning electron microscope (SEM). The results indicated that the microscopic structure of the lithium grease presents a more regular and closer network structure with long fibers, which confirms the rheological stability.

(4) This paper confirms the importance of the correlation between rheological properties and the grease microscopic structure.

(5) Finally, the optimum percentage of the CNTs in the grease composites was $2 \%$.

\section{References}

[1] F. Chinas-Castillo and H. A. Spikes, "The behavior of colloidal solid particles in Elastohydrodynamic contacts," Tribology Transactions, vol. 43, no. 3, pp. 387-394, 2000.

[2] A. V. Radulescu and I. Radulescu, "Rheological models for lithium and calcium greases," Mechanika, vol. 59, no. 3, pp. 67-70, 2006.

[3] K. Siik and J. Vuorinen, "The influence of shear thinning behavior on lubricating grease consistency and its effect on oil separation," in Proceedings of the Annual Transactions of the Nordic Rheology Conference, S. L. Mason, Ed., vol. 13, pp. 247248, The Nordic Rheology Society, Tampere, Finland, June 2005. 

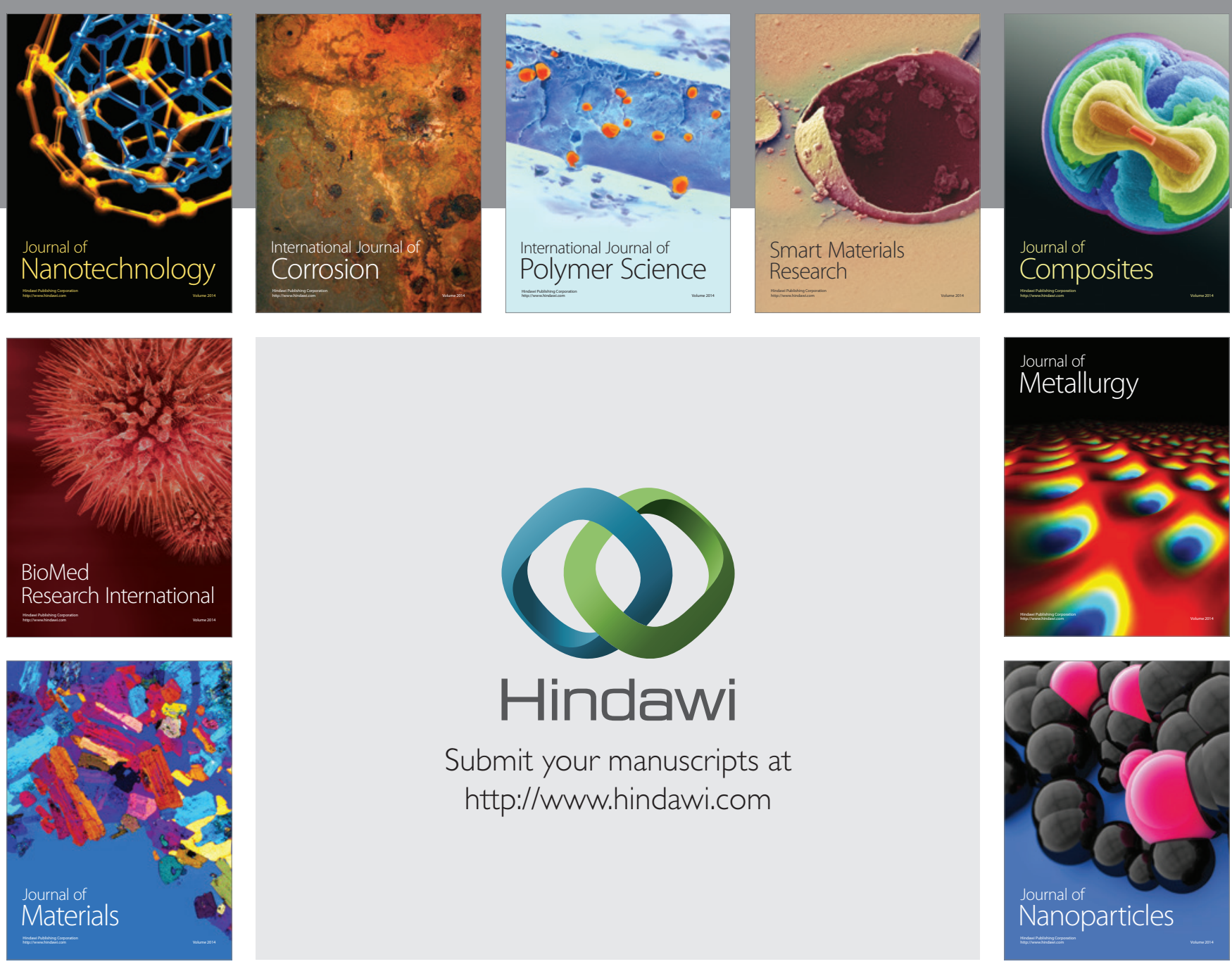

Submit your manuscripts at http://www.hindawi.com
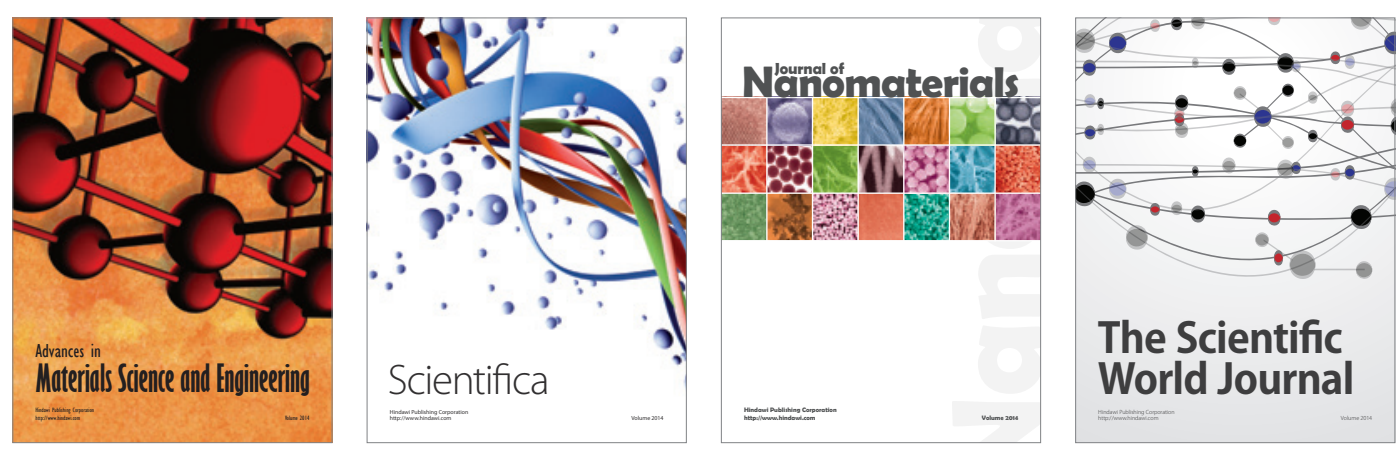

\section{The Scientific World Journal}
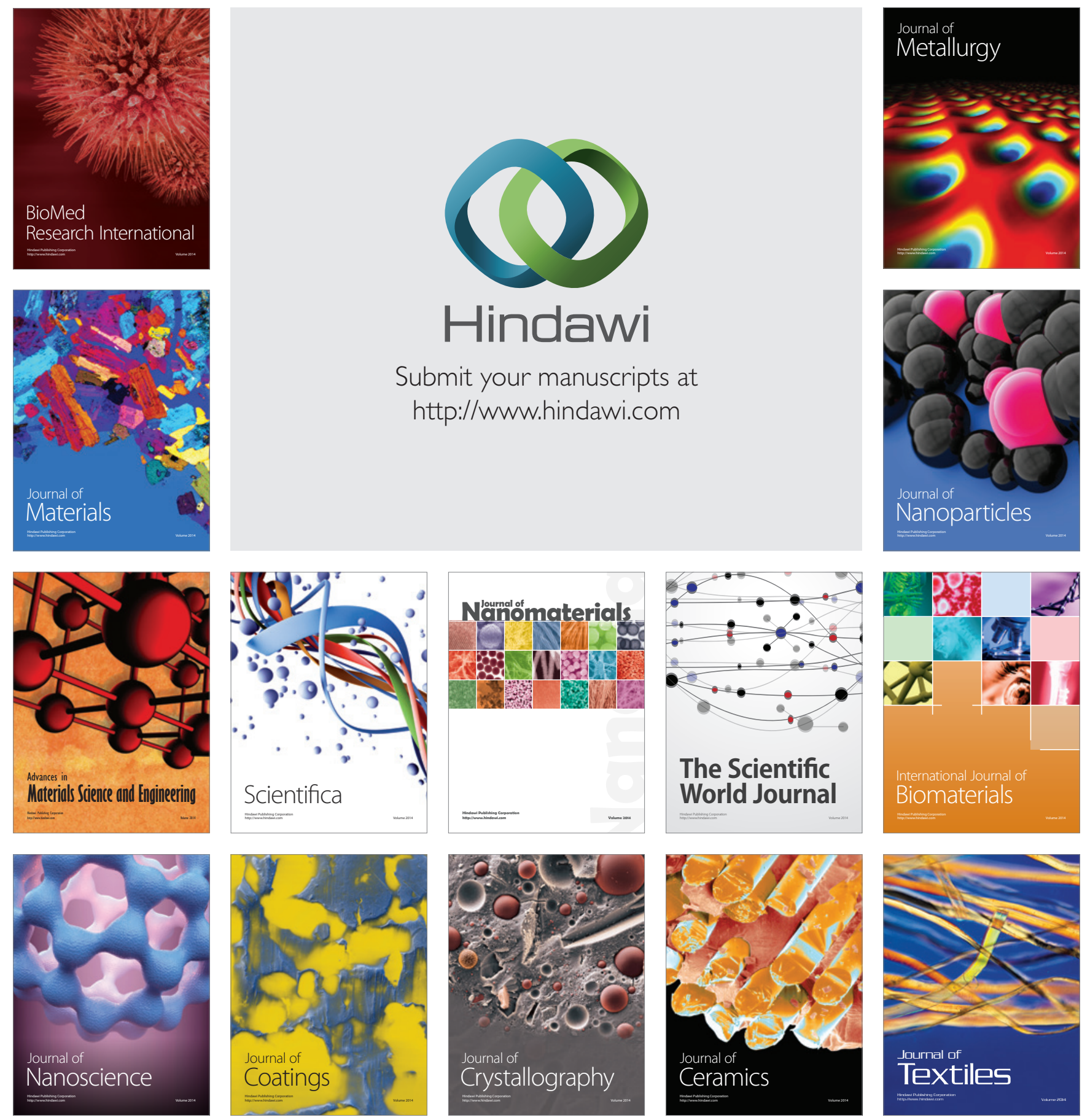